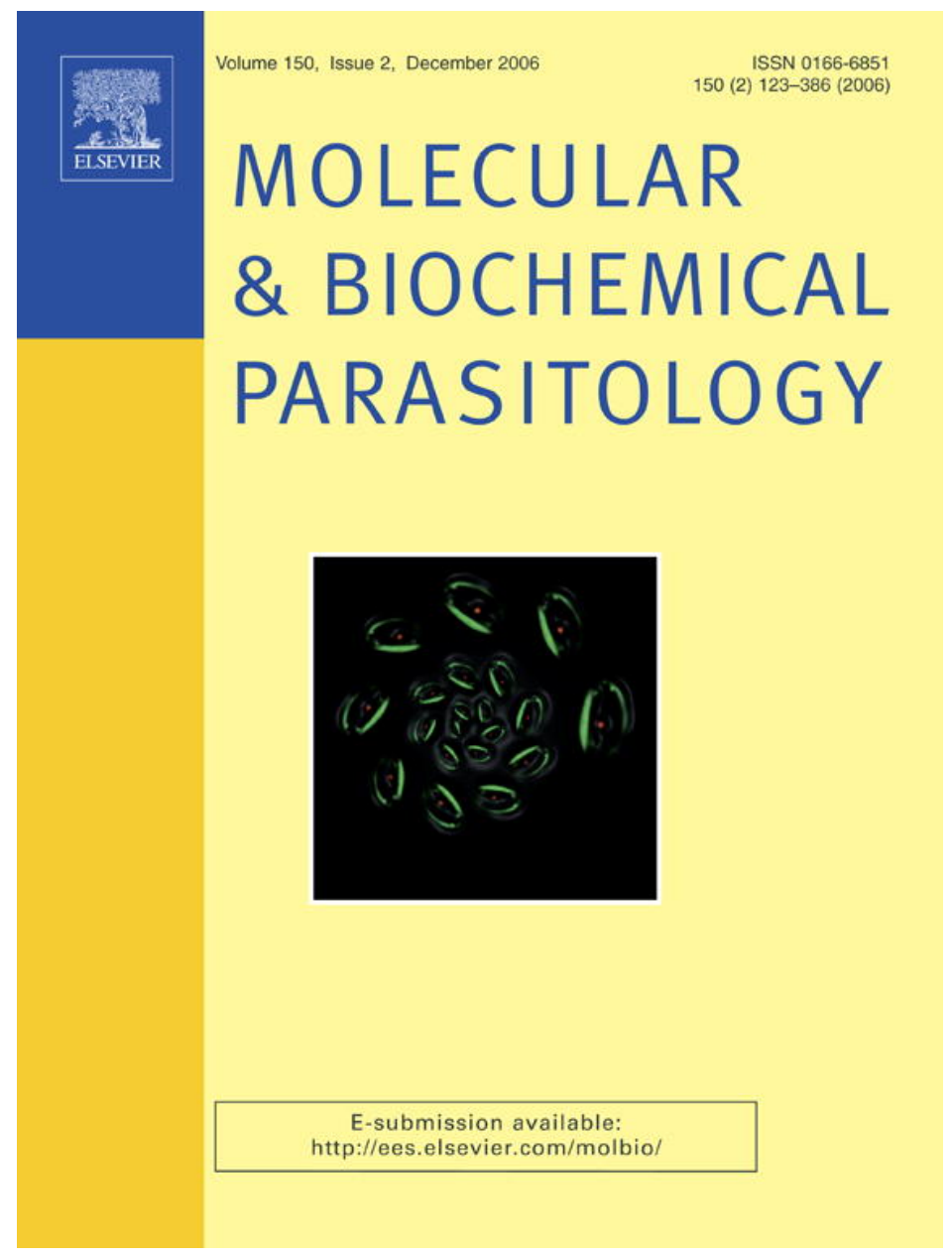

This article was originally published in a journal published by Elsevier, and the attached copy is provided by Elsevier for the author's benefit and for the benefit of the author's institution, for non-commercial research and educational use including without limitation use in instruction at your institution, sending it to specific colleagues that you know, and providing a copy to your institution's administrator.

All other uses, reproduction and distribution, including without limitation commercial reprints, selling or licensing copies or access,

or posting on open internet sites, your personal or institution's website or repository, are prohibited. For exceptions, permission may be sought for such use through Elsevier's permissions site at: 


\title{
Functional analysis of Trypanosoma brucei PUF1
}

\author{
Van-Duc Luu ${ }^{\mathrm{a}, 1}$, Stefanie Brems ${ }^{\mathrm{b}}$, Jörg D. Hoheisel ${ }^{\mathrm{b}}$, Richard Burchmore ${ }^{\mathrm{c}}$, \\ D. Lys Guilbride ${ }^{\mathrm{a}, 2}$, Christine Clayton ${ }^{\mathrm{a}, *}$ \\ ${ }^{a}$ ZMBH, Im Neuenheimer Feld 282, D-69120 Heidelberg, Germany \\ b Division of Functional Genome Analysis, Deutsche Krebsforschungszentrum, Im Neuenheimer Feld 580, 69120 Heidelberg, Germany \\ c Sir Henry Wellcome Functional Genomics Facility, Institute of Biomedical and Life Sciences, University of Glasgow, Glasgow G12 8QQ, United Kingdom \\ Received 27 July 2006; received in revised form 19 September 2006; accepted 21 September 2006 \\ Available online 18 October 2006
}

\begin{abstract}
The genomes of Trypanosoma brucei, Leishmania major and Trypanosoma cruzi each encode 10 proteins with PUF domains. PUF domain proteins from yeast and metazoa have been shown to bind RNA and to regulate mRNA stability and translation. Phylogenetic analysis suggested that the PUF proteins were duplicated and diverged early in evolution, and that most PUF proteins were lost during the evolution of mammals. Depletion of any of the first nine T. brucei PUF protein mRNAs by RNA interference had no effect on cell growth; combined depletion of PUF 1 and PUF3, PUF3 and PUF4, and PUF1 and PUF4 mRNAs also had no effect. In conflict with a previous report, procyclic trypanosomes lacking $P U F 1$ genes grew normally and we could find no evidence that PUF1 is required for growth of trypanosomes in culture. Depletion or elimination of PUF1 mRNA did not affect the abundances of any other mRNAs, as detected in microarray analysis, and also had minimal effects on the proteome. (In control experiments, treatment of bloodstream and procyclic cells with $100 \mathrm{ng} / \mathrm{ml}$ tetracycline also had no detectable effects on the transcriptome and proteome.) PUF1 preferentially bound to retroposon RNAs and was not associated with polysomes. We suggest that, as in yeast, there may be functional redundancy among the Kinetoplastid PUF proteins, or they may be involved in fine-tuning gene expression together with other proteins. Alternatively, PUF proteins may be needed in differentiating trypanosomes or in non-culturable life-cycle stages.
\end{abstract}

(C) 2006 Elsevier B.V. All rights reserved.

Keywords: Pumilio; PUF; Trypanosoma brucei; Proteome; Transcriptome

\section{Introduction}

Proteins of the PUF family have been found in virtually all eukaryotes examined [1]. The two founding members of this family were Drosophila Pumilio and C. elegans FBF. In Drosophila, Pumilio protein is known to bind the $3^{\prime}$-untranslated region ( $3^{\prime}$-UTR) of hunchback mRNA, leading to an increase in the rate of deadenylation and repression of translation of this mRNA [2,3], while in C. elegans, FBF protein binds the $3^{\prime}$ UTR of fem-3 mRNA and leads to repression of translation [4]. PUF proteins in yeast and slime moulds also repress expression of target mRNAs by binding to sequences in the $3^{\prime}$-UTR [5-7].

\footnotetext{
* Corresponding author. Tel.: +49 622154 6876; fax: +49 6221545894.

E-mail address: cclayton@zmbh.uni-heidelberg.de (C. Clayton).

1 Current address: Division of Molecular Genome Anlaysis, Deutsches Krebsforschungszentrum, Im Neuenheimer Feld 580, 69120 Heidelberg, Germany.

2 Current address: Division of Cellular Immunology, Deutsches Krebsforschungszentrum, Im Neuenheimer Feld 280, 69120 Heidelberg, Germany.
}

PUF proteins are characterized by the presence of eight consecutive repeats (Puf repeats), each consisting of approximately 40 amino acids. Each repeat contains 3 alpha helices, and the 8 repeats forms an extended crescent [8,9]. The Puf repeat region is necessary and sufficient to bind to specific RNA sequences and to effect some of the protein's biological functions. The inner surface of the crescent carries the conserved aromatic and charged amino acid residues that are likely to bind RNA, and the outer surface can contact other proteins.

The kinetoplastid genome sequences predict the presence of 10 PUF protein family members [10]. More primitive organisms, including $C$. elegans and $S$. cerevisiae, possess multiple PUF proteins, whereas only one PUF protein (with two isoforms) is present in Drosophila. Vertebrates also have a smaller number of PUF proteins $[1,4,11]$. Thus, it would appear that multiple Puf-family proteins may have emerged early in evolution, but many were lost during evolution of arthropods and vertebrates.

Functional studies of protist Puf-protein family members have so far mainly been limited to in vitro RNA binding analyses 
and so far no in vivo regulatory targets have been definitively identified. T. cruzi PUF6 [12] and PUF1 [10], and the two Puf proteins of $P$. falciparum, PfPuf1 and PfPuf2 [13], were shown to bind specifically to the Drosophila hunchback Puf recognition sequence in vitro but no further functional information on these proteins is available. T. cruzi PUF3, 5 and 8 did not show binding to the sequence in a three-hybrid assay [10].

The most extensive functional studies of protist PUF proteins so far have been of TbPUF1, which was found in a two-hybrid screen for proteins which interact with TbESAG8, a leucine repeat protein [14]. PUF1 mRNA was shown to be expressed at equal levels in both insect and bloodstream-form parasites. Attempts to disrupt the two PUF1 alleles in both bloodstreamform and procyclic-form trypanosomes by classical homologous recombination failed, but a conditional PUF 1 mutant cell line in bloodstream forms showed only a very slight growth defect upon PUF1 down-regulation. Cells that over-expressed an epitopetagged version of PUF1 had a significant growth defect and a reduced infectivity in mice.

TbESAG8 genes are located near telomeres and in subtelomeric regions [15]. They are transcribed as part of the telomeric RNA polymerase I transcription units called "VSG expression sites", which contain up to 10 "expression site associated genes" (ESAGs) and terminate with a gene encoding the variant surface glycoprotein (VSG). The results of messenger mRNA stability assays suggested that TbPUF1 might regulate stability of specific expression site (ES) derived mRNAs (e.g. ESAG8 and VSG221) in trypanosomes [14]. The interaction between TbPUF1 and ESAG8 was confirmed in pull-down assays, but the proportions of ESAG8 and PUF1 which were interacting were not measured and the biological significance of the interaction was unclear since TbPUF1 was found in the cytoplasm [14], whereas TbESAG8 is localized to the nucleolus [16].

In this report we investigated the possible function of $T b P U F 1$ in more detail, and extended the study to all other T. brucei PUF proteins.

\section{Materials and methods}

\subsection{Trypanosome culture and transfection}

Trypanosomes expressing the Tet repressor [17,18] were cultured and transfected as previously described [17,19,20]. To induce tetracycline-regulatable promoters, tetracycline was added to $100 \mathrm{ng} \mathrm{ml}^{-1}$. RNA and protein were prepared only from exponentially growing cells (less than $2 \times 10^{6} \mathrm{ml}^{-1}$ for bloodstream forms and $5 \times 10^{6} \mathrm{ml}^{-1}$ for procyclic forms). For the knockout, procyclic form 427 cells were sequentially transfected with SacI/ApaI-linearised pHD1639 (PUF1-BSD) and pHD1641 (PUF1-NPT) plasmids and selected for double resistance to neomycin and blasticidin.

\subsection{Plasmid construction}

Oligonucleotides used for PCR are listed in Table 1, which also includes the $P U F$ gene GeneDB locus numbers, and plas- mid constructs are listed in Table 2. All nine Puf open reading frames (ORFs) were amplified from T. brucei Lister 427 genomic DNA, using Expand Polymerase (Roche), and cloned into the tetracycline-inducible vectors pHD615 and pHD617 [17]. Taq polymerase was used to amplify fragments for RNA interference, which were cloned into the p2T7 series vectors [18]. Relevant segments of the plasmids were commercially sequenced. The RNAi fragment sequences and primers were chosen using RNAit [21]. For double RNAi the hygromycin cassette of p2T7-177 was replaced by a blasticidin resistance cassette.

For homozygous disruption of TbPUF1, the knockout plasmids gim5::NEO and gim5::BSD [22] were used. These contain the $N E O$ (G4218 resistance) or BSD (blasticidin resistance) cassettes, flanked by the $5^{\prime}$-splice site and $5^{\prime}$-UTR, and the $3^{\prime}$-UTR from the actin locus. Two hundred base pairs ( $5^{\prime}$-UTR) upstream and $100 \mathrm{bp}$ downstream of the ATG start codon (300 bp in total) of TbPUF1 were amplified using CZ2369 and CZ2370 and inserted upstream of the actin $5^{\prime}$-region. The last $100 \mathrm{bp}$ of the TbPUF1 ORF and 200 bp of the $3^{\prime}$-UTR were amplified with CZ2371 and CZ2372 and inserted downstream of the actin $3^{\prime}-$ region.

\subsection{Antisera}

Generation of peptides and immunisation of rabbits were done by Eurogentec (Brussels, Belgium). The C-terminal peptide 'RELARKNGNQKNKKRW' (aa-residue 445-460 of TbPUF1) was synthesized and $5 \mathrm{mg}$ were coupled to KLH. Two rabbits were immunized (500 ng each) with the peptide followed by three individual boosters (again $500 \mathrm{ng}$ each) at days 14, 28 , and 56. Serum was taken at day 0 (pre-immune, PPI), day 38 (small bleeding), day 66 (large bleeding), and day 87 (final bleeding). The specificity and titre of the antiserum were tested by Western blotting. Antibodies were affinity purified using Affi-Gel 10 (BioRad 153-6064) according to the manufacturer's instructions.

\subsection{Northern and Western blots}

For Northern blotting $10 \mu \mathrm{g}$ of total RNA were separated on formaldehyde gels and blotted onto membrane (Nitre ${ }^{\circledR}$ Schleicher and Schuell) using a Turbo-blotter apparatus. Probes for the Northern blots were synthesised by random priming or PCR with ${ }^{32} \mathrm{P}$ label. Blot signals were quantitated by phosphorimager. The control antibodies for the Western blots were a rabbit anti-peptide antibody reacting with a cytosolic protein (CSM) $[23,24]$ or antibody to aldolase [25]. Detection was by ECL (Amersham, Braunschweig) according to the manufacturer's instructions.

Polysomes were analysed on sucrose gradients as described in [26] in the presence of $100 \mu \mathrm{g} / \mathrm{ml}$ cycloheximide; as a control the same procedure was repeated without cycloheximide and in the presence of $20 \mathrm{mM}$ EDTA. The position of ribosomes on the gradient was determined by examining the RNA by gel electrophoresis. 
Table 1

Oligonucleotides used to amplify complete open reading frames, RNAi fragments and flanking regions of the nine $T b P U F$ genes

\begin{tabular}{|c|c|c|c|}
\hline ORF, size & Primers & Sequence & Comments \\
\hline TbPUF1 & CZ1769 5' & GATCAAGCTTATGTCGTCGGATGAGG & HindIII \\
\hline Tb10.70.2800 & $\mathrm{CZ} 17703^{\prime}$ & CGAGGATCCCTATGTTCCTTTCTTG & BamHI \\
\hline $1701 \mathrm{bp}$ & $\mathrm{CZ} 21363^{\prime}$ & GATCGGATCCTGTTCCTTTCTTGCTT & BamHI, -stop \\
\hline RNAi, 389 bp & CZ1811 3' & GATCCCCGGGTGTTCCTTTCTTG & Sma I, -stop \\
\hline Knock-out & 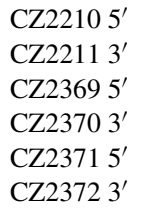 & $\begin{array}{l}\text { GATCctcgagGCGCCAGAACATCTTAAAGC } \\
\text { GATCggatccCGACTTTGCCTCCACTCTTC } \\
\text { GATCGAGCTCAGAAGAGAAACGGCTC } \\
\text { GATCactagtGTTCAGCAGTTCTTATC } \\
\text { GATCggatccACAGCAGTTTCCAATG } \\
\text { GATCGGGCCCAACAGTTTTTCTCTAAC }\end{array}$ & $\begin{array}{l}\text { XhoI } \\
\text { Bam } \mathrm{HI} \\
\text { SacI } \\
\text { SpeI } \\
\text { Bam } \mathrm{HI} \\
\text { ApaI }\end{array}$ \\
\hline TbPUF2 & $\mathrm{CZ2280} 5^{\prime}$ & GATCaagcttATGTCTGGTTGGGACG & HindIII \\
\hline Tb10.389.0940 & CZ2281 3' & GATCggatccCTACAGCGTTGGCATG & BamHI \\
\hline $2544 \mathrm{bp}$ & CZ2282 3' & GATCgttaacCAGCGTTGGCATGCAG & HpaI, -stop \\
\hline RNAi, 501 bp & $\begin{array}{l}\mathrm{CZ2283} 5^{\prime} \\
\mathrm{CZ} 22843^{\prime}\end{array}$ & $\begin{array}{l}\text { CGAGCTAAAGGATTGCCTTG } \\
\text { TCCTGCATCATAAGCACGAG }\end{array}$ & \\
\hline TbPUF3 & $\mathrm{CZ} 21305^{\prime}$ & GATCaagcttATGTGTTCCAGTTCCC & HindIII \\
\hline Tb10.100.0190 & $\mathrm{CZ} 21313^{\prime}$ & GATCagatctTCAGCCGGAGAGCGGT & $B g l \mathrm{II}$ \\
\hline $1758 \mathrm{bp}$ & $\begin{array}{l}\mathrm{CZ2132} 3^{\prime} \\
\mathrm{CZ} 22743^{\prime}\end{array}$ & $\begin{array}{l}\text { GATCagatctGCCGGAGAGCGGTTGG } \\
\text { GATCgttaacGCCGGAGAGCGGTTGG }\end{array}$ & $\begin{array}{l}\text { BglII, -stop } \\
\text { HpaI, -stop }\end{array}$ \\
\hline RNAi, 555 bp & $\begin{array}{l}\text { CZ2206 5' } \\
\text { CZ2207 } 3^{\prime}\end{array}$ & $\begin{array}{l}\text { GATCgtcgacCGGACGATAATGAGCGAAATTG } \\
\text { GATCagatctTGCAATCGTGTCAATGGTTTTG }\end{array}$ & $\begin{array}{l}B g l \mathrm{II} \\
B g l \mathrm{II}\end{array}$ \\
\hline $\begin{array}{l}\text { TbPUF4 } \\
\text { Tb927.6.820 }\end{array}$ & $\begin{array}{l}\mathrm{CZ} 21335^{\prime} \\
\mathrm{CZ} 21343^{\prime}\end{array}$ & $\begin{array}{l}\text { GATCaagcttATGGAGGCCAGTGCCGAGGTG } \\
\text { GATCggatccTCATCCCTTCCTGCCGCGTTG }\end{array}$ & $\begin{array}{l}\text { HindIII } \\
\text { Bam HI }\end{array}$ \\
\hline $2967 \mathrm{bp}$ & $\begin{array}{l}\text { CZ2135 } 3^{\prime} \\
\text { CZ2258 } 3^{\prime}\end{array}$ & $\begin{array}{l}\text { GATCggatccTCCCTTCCTGCCGCGTTGCG } \\
\text { GATCgttaacTCCCTTCCTGCCGCGT }\end{array}$ & $\begin{array}{l}\text { BamHI, -stop } \\
\text { HpaI, -stop }\end{array}$ \\
\hline RNAi, 459 bp & $\begin{array}{l}\text { CZ2208 5 } \\
\text { CZ2209 } 3^{\prime}\end{array}$ & $\begin{array}{l}\text { GATCctcgagGCATCTGCAACGAACTCAAAAAGC } \\
\text { GATCggatccAGCACATCAAGCATCGTCTGCAC }\end{array}$ & $\begin{array}{l}\text { XhoI } \\
\text { BamHI }\end{array}$ \\
\hline $\begin{array}{l}\text { TbPUF5 } \\
\text { Tb927.7.4730 }\end{array}$ & $\begin{array}{l}\text { CZ2259 5 } \\
\text { CZ2260 } 3^{\prime}\end{array}$ & $\begin{array}{l}\text { GATCaagcttATGCTTCGTAGGGGTG } \\
\text { GATCggatccTCACTCACCGACTGCC }\end{array}$ & $\begin{array}{l}\text { HindIII } \\
\text { Bam } \mathrm{HI}\end{array}$ \\
\hline 1293 bp & $\begin{array}{l}\text { CZ2261 } 3^{\prime} \\
\text { CZ2529 } 3^{\prime}\end{array}$ & $\begin{array}{l}\text { GATCgttaacCTCACCGACTGCCCCG } \\
\text { GATCGGATCCCTCACCGACTGCCCCGG }\end{array}$ & $\begin{array}{l}\text { HpaI, -stop } \\
\text { BamHI, -stop }\end{array}$ \\
\hline RNAi, 436 bp & $\begin{array}{l}\text { CZ2262 } 5^{\prime} \\
\mathrm{CZ} 22633^{\prime}\end{array}$ & $\begin{array}{l}\text { CTTGCTGTGAGTTCGCCATA } \\
\text { TGACGGGATCACACACTGTT }\end{array}$ & \\
\hline $\begin{array}{l}\text { TbPUF6 } \\
\text { Tb10.26.0140 } \\
2532 \mathrm{bp}\end{array}$ & $\begin{array}{l}\mathrm{CZ} 22755^{\prime} \\
\mathrm{CZ} 22763^{\prime} \\
\mathrm{CZ} 22773^{\prime}\end{array}$ & $\begin{array}{l}\text { GATCaagcttATGAGTTCAACCAAAG } \\
\text { GATCggatccTCACTCGGCATCGAAG } \\
\text { GATCgttaacCTCGGCATCGAAGTGC }\end{array}$ & $\begin{array}{l}\text { HindIII } \\
\text { Bam HI } \\
\text { HpaI, -stop }\end{array}$ \\
\hline RNAi, 479 bp & $\begin{array}{l}\mathrm{CZ2278} 5^{\prime} \\
\mathrm{CZ} 22793^{\prime}\end{array}$ & $\begin{array}{l}\text { TTATTCAGCGTGCAGTGGAG } \\
\text { AAAAATGGCTTCCTCCTGGT }\end{array}$ & \\
\hline $\begin{array}{l}\text { TbPUF7 } \\
\text { Tb11.01.6600 } \\
2115 \text { bf }\end{array}$ & $\begin{array}{l}\mathrm{CZ} 22855^{\prime} \\
\mathrm{CZ} 22863^{\prime} \\
\mathrm{CZ} 22873^{\prime}\end{array}$ & $\begin{array}{l}\text { GATCaagcttATGCCAAAAATGCGTTTAG } \\
\text { GATCtgatcaTCATTCGGCCGTTTTG } \\
\text { GATCgttaacTTCGGCCGTTTTGAAAG }\end{array}$ & $\begin{array}{l}\text { HindIII } \\
\text { BclI } \\
\text { HpaI, -stop }\end{array}$ \\
\hline RNAi, 583 bp & $\begin{array}{l}\text { CZ2288 } 5^{\prime} \\
\text { CZ2289 } 3^{\prime}\end{array}$ & $\begin{array}{l}\text { GACCCTGTTTCGTCACCTGT } \\
\text { TCATAAGATGCTTGCGTTGC }\end{array}$ & \\
\hline $\begin{array}{l}\text { TbPUF8 } \\
\text { Tb927.3.2470 } \\
1815 \text { bp }\end{array}$ & $\begin{array}{l}\mathrm{CZ} 22485^{\prime} \\
\mathrm{CZ} 22493^{\prime} \\
\mathrm{CZ} 22503^{\prime}\end{array}$ & $\begin{array}{l}\text { GATCaagcttATGGGTAAAACTAACAC } \\
\text { GATCggatccTTATTTCTTGGGGAGA } \\
\text { GATCgttaacTTTCTTGGGGAGAACC }\end{array}$ & $\begin{array}{l}\text { HindIII } \\
\text { BamHI } \\
\text { HpaI, -stop }\end{array}$ \\
\hline RNAi, 303 bp & $\begin{array}{l}\text { CZ2251 5 } \\
\text { CZ2252 } 3^{\prime}\end{array}$ & $\begin{array}{l}\text { TCAACAGTCCCTTTGGACATC } \\
\text { TTGCAATGAGACCCACGTAA }\end{array}$ & \\
\hline TbPUF9 & $\mathrm{CZ1857} 5^{\prime}$ & GATCAAGCTTatggaagtacgcgatg & HindIII \\
\hline
\end{tabular}


Table 1 (Continued)

\begin{tabular}{|c|c|c|c|}
\hline ORF, size & Primers & Sequence & Comments \\
\hline Tb927.1.2600 & $\mathrm{CZ1858} 3^{\prime}$ & GATCGGATCCctaacattctccgtca & BamHI \\
\hline \multirow[t]{4}{*}{2004 bp } & $\mathrm{CZ1889} 5^{\prime}$ & gatcGAGCTCatggaagtacgcgatg & SacI \\
\hline & $\mathrm{CZ} 21373^{\prime}$ & GATCagatctACATTCTCCGTCATCA & BglII, -stop \\
\hline & $\mathrm{CZ1886} 3^{\prime}$ & GATCctcgagGTTAACacattctccgtcatca & XhoI, HpaI, -stop \\
\hline & CZ1920 3' & GAAGATCTGGCGTAGTCTGGGACGTCGTATGGGTAACATTCTCCGTCATC & BglII, -stop, +HA-tag \\
\hline \multirow[t]{6}{*}{ RNAi, 371 bp } & $\mathrm{CZ} 20375^{\prime}$ & gatcGTCGACggatgccgctttagtgg & $B g l \mathrm{II}$ \\
\hline & $\mathrm{CZ} 20383^{\prime}$ & gatcAGATCTcaaggcaacatgggcga & $B g l \mathrm{II}$ \\
\hline & $\mathrm{CZ} 24125^{\prime}$ & GTCAGAGCTCGGGTAGAAGTAAAGG & SacI \\
\hline & $\mathrm{CZ} 24133^{\prime}$ & CTAGGCTAGCAAGAGGGAATGGCCC & NheI \\
\hline & $\mathrm{CZ} 23755^{\prime}$ & GATCggatccAAATAGGCGGCAGAGC & BamHI \\
\hline & $\mathrm{CZ} 23763^{\prime}$ & GATCGGGCCCAAAAGTACATAAGTAC & ApaI \\
\hline
\end{tabular}

Table 2

Plasmid constructs containing complete open reading frames and RNAi fragments of the nine TbPUF genes.

\begin{tabular}{|c|c|}
\hline pHD1377 & pHD615 + PUF1-cds at HindIII/BamHI \\
\hline pHD1378 & pHD617 + PUF1-cds at HindIII/BamHI \\
\hline pHD1396 & pHD918 + PUF1-cds (w/o stop) at HindIII/(SmaI/HpaI) \\
\hline pHD1538 & p2T7 + PUF1-RNAi at XhoI/BamHI \\
\hline pHD1639 & PUF1 KO, blasticidin resistance \\
\hline pHD1641 & $P U F 1 \mathrm{KO}$, neomycin resistance \\
\hline pHD1564 & pHD615 + PUF2-cds at HindIII/BamHI \\
\hline pHD1565 & pHD617 + PUF2-cds at HindIII/BamHI \\
\hline pHD1548 & p2T7 ${ }^{\mathrm{TA}}$-blue $+P U F 2$-RNAi at TA-overhang \\
\hline pHD1490 & pHD615 + PUF3-cds at HindIII/(BglII/BamHI $)$ \\
\hline pHD1491 & pHD617 + PUF3-cds at HindIII/(BglIII/BamHI $)$ \\
\hline pHD1539 & p2T7 + PUF3-RNAi at $(B g l \mathrm{II} / \mathrm{X} h o \mathrm{I}) /(B g l \mathrm{II} / \mathrm{BamH \textrm {H }})$ \\
\hline pHD1650 & 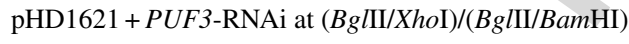 \\
\hline pHD1492 & pHD615 + PUF4-cds at HindIII/BamHI \\
\hline pHD1493 & pHD617 + PUF4-cds at HindIII/BamHI \\
\hline pHD1540 & p2T7 + PUF4-RNAi at $X h o \mathrm{I} / B a m \mathrm{HI}$ \\
\hline pHD1651 & pHD1621 + PUF4-RNAi at XhoI/BamHI \\
\hline pHD1556 & pHD615 + PUF5-cds at HindIII/BamHI \\
\hline pHD1557 & pHD617 + PUF5-cds at HindIII/BamHI \\
\hline pHD1699 & pHD1484 + PUF5-cds (w/o stop) at HindIII/BamHI \\
\hline pHD1652 & pHD1621 + PUF5-RNAi at XhoI/BamHI \\
\hline pHD1702 & pHD918 + PUF5-cds (w/o stop) at HindIII/HpaI \\
\hline pHD1544 & $\mathrm{p} 2 \mathrm{~T}^{\mathrm{TA}}$-blue $+P U F 5$-RNAi at TA-overhang \\
\hline pHD1562 & pHD615 + PUF6-cds at HindIII/BamHI \\
\hline pHD1563 & pHD617 + PUF6-cds at HindIII/BamHI \\
\hline pHD1547 & $\mathrm{p} 2 \mathrm{~T}^{\mathrm{TA}}$-blue $+P U F 6$-RNAi at TA-overhang \\
\hline pHD1653 & pHD1621 + PUF6-RNAi at XhoI/BamHI \\
\hline pHD1554 & pHD615 + PUF7-cds at HindIII/(BclI/BamHI $)$ \\
\hline pHD1555 & pHD617 + PUF7-cds at HindIII/(BclI/BamHI) \\
\hline pHD1543 & $\mathrm{p} 2 \mathrm{~T}^{\mathrm{TA}}$-blue $+P U F 7-\mathrm{RNAi}$ at TA-overhang \\
\hline pHD1654 & pHD1621 + PUF7-RNAi at XhoI/BamHI \\
\hline pHD1552 & pHD615 + PUF8-cds at HindIII/BamHI \\
\hline pHD1553 & pHD617 + PUF8-cds at HindIII/BamHI \\
\hline pHD1542 & $\mathrm{p} 2 \mathrm{~T}^{\mathrm{TA}}$-blue $+P U F 8$-RNAi at TA-overhang \\
\hline pHD1411 & pHD615 + PUF9-cds at HindIII/BamHI \\
\hline pHD1412 & pHD617 + PUF9-cds at HindIII/BamHI \\
\hline pHD1489 & 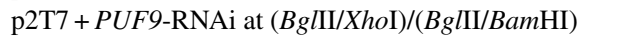 \\
\hline
\end{tabular}

\subsection{Microarrays}

RNA preparation and analysis methods were similar to those previously described $[27,28]$. Briefly, for the genome-wide analysis of gene expression, $15 \mu \mathrm{g}$ of total RNA was incubated for $5 \mathrm{~min}$ at $65^{\circ} \mathrm{C}$ with $500 \mathrm{ng}$ of oligo d(T) $)_{12-18}$ (Amersham), 30 mM dAGT-mix, 2 mM dCTP and 2 mM Cy3 (or Cy5) labelled $\mathrm{dCTP}$ (Amersham). The mixture was put on ice before addition of $8 \mu \mathrm{l}$ of $5 \times$ superscript buffer (Invitrogen), $2 \mu 10.1 \mathrm{M}$ DTT, $1 \mu \mathrm{l}$ SuperScript III RT (Invitrogen). The reaction was incubated at $50{ }^{\circ} \mathrm{C}$ overnight. Afterwards the reaction was inactivated at $70{ }^{\circ} \mathrm{C}$ for $15 \mathrm{~min}$. One microlitre $\mathrm{RNaseH}$ (Roche) was added and the reaction incubated at $37^{\circ} \mathrm{C}$ for $20 \mathrm{~min}$. The cDNA was then purified using QIAquick PCR purification columns, ethanol precipitated and resuspended in $10 \mu \mathrm{l}$ hybridization buffer.

Arrays of 23,000 [27] or 24,000 [28] random $2 \mathrm{~kb}$ genomic fragments on glass slides were pre-incubated in $5 \times \mathrm{SSC}, 0.1 \%$ SDS and $1 \% \mathrm{BSA}$ for $1 \mathrm{~h}$ at $42{ }^{\circ} \mathrm{C}$, dipped in water then isopropanol and allowed to dry. Hybridization with mixed Cy3and Cy5-labelled cDNAs was in 50\% deionised formamide, $5 \%$ dextran sulfate, $3 \times$ SSC, $1 \%$ SDS and $5 \times$ Denhardts solution at $42{ }^{\circ} \mathrm{C}$ for $16 \mathrm{~h}$, using $24-60 \mathrm{~mm}$ cover slips and glass array hybridisation cassettes (Ambion). Slides were then washed for 5 min each in $1 \times \mathrm{SSC}, 0.2 \% \mathrm{SDS}, 0.1 \times \mathrm{SSC}, 0.2 \% \mathrm{SDS}$, and $0.1 \times \mathrm{SSC}$ at room temperature. The results were analysed as previously described [27,28] using M-CHIPS software [29,30]. To choose regulated clones for sequence analysis we selected only those with the following parameters-fitted intensities: at least 50,000; $\mathrm{min} / \mathrm{max}$-separation: 0.2 ; ratio for RNAi induced versus uninduced: at least 2.0 or -2.0 .

To find RNAs bound to PUF1, the TAP-tagged protein was purified as described in [31] with minor modifications. Washed pellets of $5 \times 10^{9}$ cells were either stored in liquid nitrogen or used directly. The cells were broken in $6 \mathrm{ml}$ breakage buffer (10 mM Tris-Cl, $10 \mathrm{mM} \mathrm{NaCl}, 0.1 \%$ IGEPAL, adjusted to $\mathrm{pH}$ 7.8 with $\mathrm{HCl}$ ) including one tablet of complete inhibitor (without EDTA, Roche), 200 units RNAseIn (Promega) and $5 \mu$ l Vanadyl Ribonucleoside complexes (Sigma) by passing 15-20 through a 21-25 gauge needle. The lysate was centrifuged at $10,000 \times g$ for $15 \mathrm{~min}$ to remove cell debris and the supernatant was cleared at $35,000 \mathrm{rpm}, 4^{\circ} \mathrm{C}$, for $45 \mathrm{~min}$. Binding to $200 \mathrm{ml} \mathrm{IgG}$ sepharose bead suspension (Amersham Biosciences), washing, and TEV 
cleavage were done as described [31], but TEV cleavage buffer was supplemented with 200 units RNaseIn and $5 \mu$ l Vanadyl Ribonucleoside complexes. The eluate after the TEV cleavage was supplemented with $0.1 \%$ SDS and $30 \mu \mathrm{g}$ proteinase $\mathrm{K}$, and incubated for $30 \mathrm{~min}$ in at $55^{\circ} \mathrm{C}$. The immunoprecipitated RNA was isolated by phenol-chloroform-isoamyl alcohol extraction and ethanol precipitation.

\subsection{Polysomes}

Polysome isolation was adapted from [26]. Briefly, $5 \times 10^{8}$ to $2 \times 10^{9}$ cells were collected by centrifugation at $2000 \times g$ for $5 \mathrm{~min}$ and washed twice with ice-cold polysome buffer. Cells were resuspended in $0.5 \mathrm{ml}$ of polysome buffer and lysed by the addition of NP-40 (final $0.2 \%$ ). The cell suspension was homogenised and the lysate was cleared by centrifugation at $10,000 \times g$ for $4 \mathrm{~min}$. Cleared lysate from $5 \times 10^{8}$ cells was layered onto $15-50 \%$ sucrose gradients prepared in polysome buffer and centrifuged at $4{ }^{\circ} \mathrm{C}$ for $2 \mathrm{~h}$ at $36,000 \mathrm{rpm}$ in a Beckman SW41 rotor, and $1 \mathrm{ml}$ fractions were collected. For protein sample preparations, the eluates were precipitated with $1 \mathrm{ml}$ of $20 \%$ TCA and protein pellets washed three times with acetone. For RNA extraction, each fraction was precipitated with $1 \mathrm{ml}$ of isopropanol, and the material was collected by centrifugation. Pellets were resuspended in $0.3 \mathrm{ml}$ of a solution containing $10 \mathrm{mM}$ Tris- $\mathrm{HCl}$ (pH 7.5), $1 \mathrm{mM}$ EDTA, $100 \mu \mathrm{g} / \mathrm{ml}$ proteinase$\mathrm{K}$, and $1 \% \mathrm{SDS}$ and incubated at $65^{\circ} \mathrm{C}$ for $30 \mathrm{~min}$. The sample was precipitated with 1 volume of isopropanol after addition of $20 \mu \mathrm{g}$ of glycogen and $\mathrm{NaCl}$ to $600 \mathrm{mM}$.

\subsection{Proteomics}

About $2 \times 10^{8}$ cells were lysed in $500 \mu$ l DIGE lysis buffer and the lysate was cleared twice at $13,000 \mathrm{rpm}$ at $4{ }^{\circ} \mathrm{C}$ for $10 \mathrm{~min}$. One volume of $20 \%$ TCA was added and incubation was done on ice for $30 \mathrm{~min}$ (or overnight). Protein was precipitated with $20 \%$ TCA on ice, and pelleted at $13,000 \mathrm{rpm}$ for $10 \mathrm{~min} 4{ }^{\circ} \mathrm{C}$, then washed three times with cold acetone. After drying for $10 \mathrm{~min}$ at room temperature the pellet was dissolved in DIGE lysis buffer at protein concentration $>5 \mathrm{mg} \mathrm{ml}^{-1}$ and the $\mathrm{pH}$ adjusted to 8.5. The protein pellet is somewhat difficult to dissolve: vortexing, grinding and passing through a 21-25 gauge needle was sometimes necessary. About 400 pmol CyDye was added to $10 \mu$ l protein sample, mixed immediately and incubated on ice for $30 \mathrm{~min}$ in the dark, then the reaction was stopped with $1 \mu \mathrm{l}$ of $10 \mathrm{mM}$ lysine. The Cy 3 and Cy5-labelled proteins samples were mixed and $40 \mu \mathrm{l}$ of each unlabelled protein sample $(5 \mathrm{mg} / \mathrm{ml})$ was added. Mixed samples were then subjected to 2D electrophoresis using $\mathrm{pH} 3-10$ non-linear IPG strips in the first dimension and $12 \%$ SDS-PAGE in the second dimension. The gel was scanned subsequently with the Cy3- and Cy5-channel at $100 \mu \mathrm{m}$ resolution using a Typhoon Imaging scanner 9400 (Amersham Biosciences). Representative spots were picked for normalisation over the two channels using Typhoon Scanner Control Software, Version 3.0 and ImageQuant Tools software, Version 3.0. Two independent DIGE analyses were performed for each cell line, and we looked for spots which differed by at least three-fold between gels. As a control, we analysed the effect of a $48 \mathrm{~h}$ tetracycline incubation on the proteomes of Lister 427 bloodstream-form and procyclic form trypanosomes expressing T7 polymerase and the tet repressor (containing pHD1313 and pHD514). Importantly, tetracycline had no detectable effect on the proteomes of the control cells (not shown).

Regulated spots were selected using DeCyder Software and $1.4 \mathrm{~mm}$ gel plugs were cut and subjected to in-gel trypsin digest in an Ettan Spot Handing Workstation (GE Healthcare), following standard protocols. The resulting tryptic peptides were solubilized in $0.5 \%$ formic acid and fractionated by nanoflow HPLC on a C18 reverse phase column, eluting with a continuous linear gradient to $40 \%$ acetonitrile over $20 \mathrm{~min}$. Eluate was analysed by online electrospray tandem mass spectrometry using a Qstar Pulsar (Applied Biosystems).

Mass spectrometric analysis was performed in IDA mode (AnalystQS software, Applied Biosystems). Peaks were extracted using the Mascot script (BioAnalyst, Applied Biosystems) and automatically exported to the Mascot (Matrix Science) search engine. Protein identification was achieved by searching the complete T. brucei genome, maintained on a local Mascot server.

\section{Results}

\subsection{The 10 PUF proteins of T. brucei}

There are 10 T. brucei PUF proteins whose structures resemble those of the T. cruzi PUFs [10]. We did however note the presence of a predicted transmembrane helix in TbPUF3 and a putative mitochondrial localization signal in TbPUF5. Since the relationship of kinetoplastid PUF proteins to those of other eukaryotes had not previously been investigated, we generated a phylogenetic tree using only the PUF domains from 90 Puf family members (Fig. 1). We found that PUF proteins of vertebrates (yellow) form a subfamily, and that they are closest related to Puf members of Dipterans. In contrast to a previous phylogenetic analysis using only 34 Puf domain amino acid sequences [13] no obvious separation between plant and animal PUF members could be drawn. Kinetoplastid PUF members are spread throughout the eukaryotic lineage, as is true for yeast PUF proteins. This suggests that PUF proteins lost their diversity in the course of evolution.

\subsection{Reduced expression of TbPUF mRNAs and of TbPUF1 protein does not affect growth}

To investigate the roles of PUF proteins in T. brucei, RNAi knockdown was performed for the first $9 P U F$ genes in bloodstream and procyclic cells. (PUF10 appeared in the database after this study was completed so will not be discussed further in this paper.) To check the effectiveness of RNAi, tetracycline was added and total RNA was prepared after $48 \mathrm{~h}$ (Fig. 2A). The efficiency of transcript down-regulation ranged from $82 \%$ (TbPUF3) to only 25\% (TbPUF6). Increasing the tetracycline concentration did not lead to higher RNAi efficiency and several clones were always tested; we do not know why it was not 


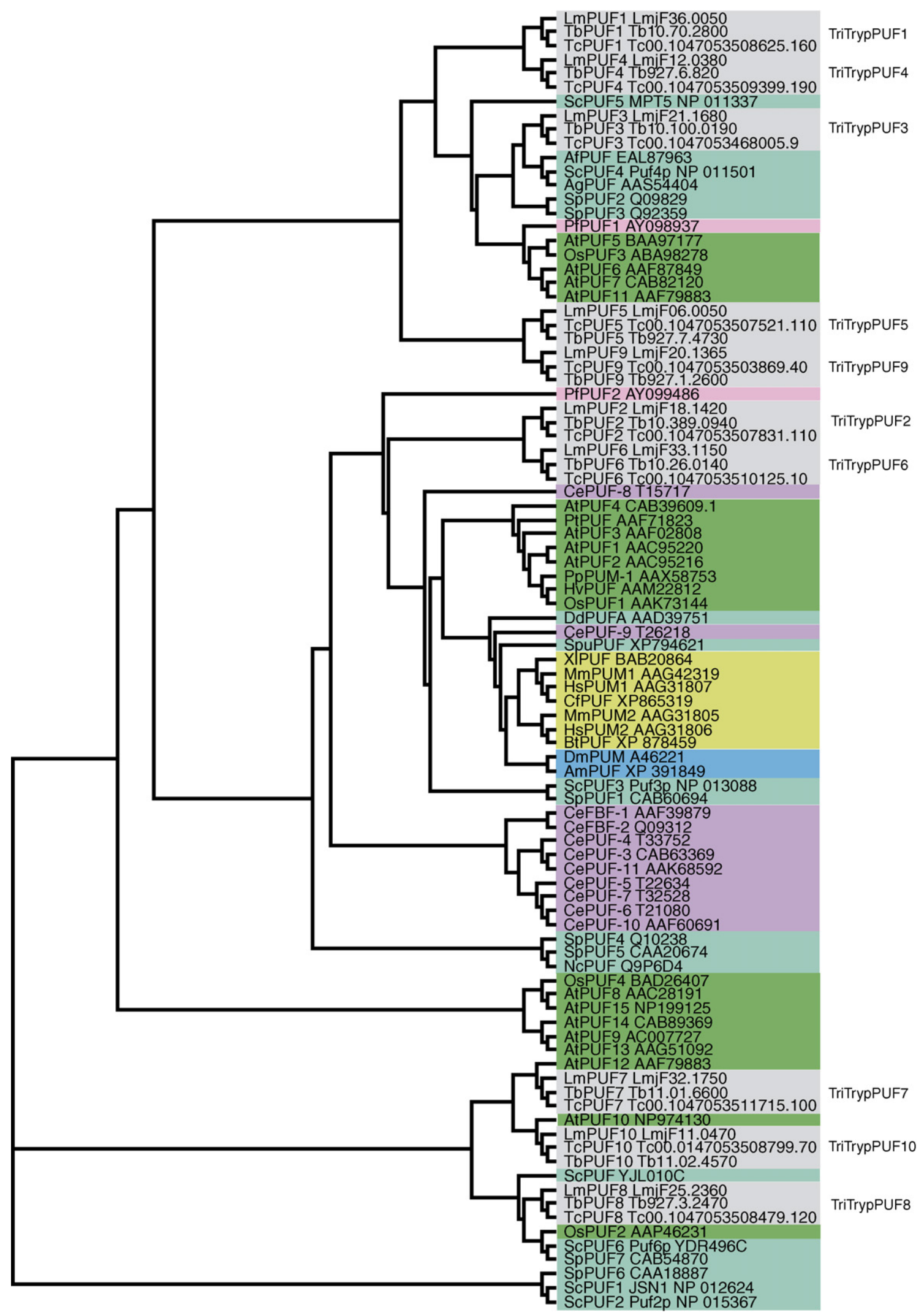

Fig. 1. PUF proteins throughout eukaryotes. A phylogenetic tree was derived by aligning only the PUF domains from 90 Puf members. Af, Aspergillus fumigatus; $\mathrm{Ag}$, Ashbya gossypii; Am, Apis mellifera; At, Arabidopsis thaliana; Bt, Bos taurus; Ce, Caenorhabditis elegans; Cf, Canis familiaris; Dd, Dictyostelium discoideum; $\mathrm{Dj}$, Dugesia Japonica; Dm, Drosophila melanogaster; Hs, Homo sapiens; Hv, Hordeum vulgare; Lm, Leishmania major; Mm, Mus musculus; Nc, Neurospora crassa; Os, Oryza sativa; Pf, Plasmodium falciparum; Pp, Physcomitrella patens; $\mathrm{Pt}$, Populus tremula; Rn, Ratus norvegicus; Sc, Saccharomyces cerevisiae; Sp, Schizosach haromyces pombe; $\mathrm{Spu}$, Strongylocentrotus purpuratus; Tb, Trypanosoma brucei; Tc, Trypanosoma cruzi; X1, Xenopus laevis. GenBank accession numbers identify each entry. Different groups of organisms are denoted by different colours. 


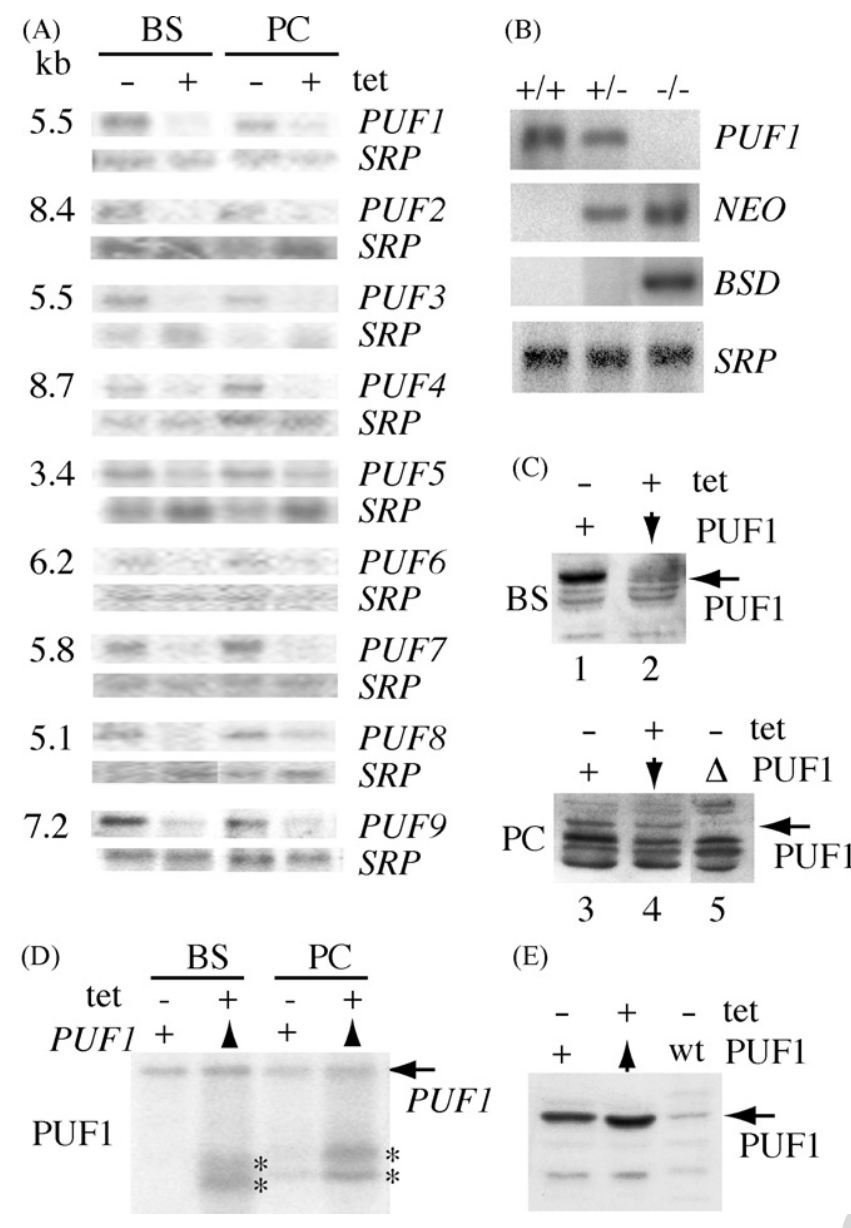

Fig. 2. (A) Northern blot showing down-regulation of $T b P U F$ transcripts. Equal amounts of RNA $(10 \mu \mathrm{g})$ from RNAi uninduced (-) and induced (+) bloodstream (BS) and procyclics (PC) cells were loaded on each lane. Tet: addition of tertracycline. After probing for TbPUF transcripts, the same filter was hybridised with SRP (signal recognition particle RNA) as a loading control. TbPUF transcript sizes are indicated on the left. (B) Northern blot analysis of procyclic wild-type (+/+), hemizygous (+/-) and $\triangle P U F 1(-/-)$ cells. Ten milligrams of total RNA was loaded onto each lane. Probes are shown on the right. (C) Western blot using $\alpha-T b$ PUF1 to assess PUF1 protein expression level in procyclic (PC) and bloodstream form (BS) cells and in TbPUF1 RNAi (1538) uninduced (-) and induced (+) cell lines. Cytosolic marker (CSM) was used as a loading control. The antibody cross-reacts with different bands in procyclic and bloodstream cells. (D) Over-expression of PUF1 mRNAs in bloodstream and procyclic trypanosomes assessed by Northern blotting. The endogenous RNA is indicated by an arrow and the induced RNAs by asterisks (*). (E) Over-expression of PUF1 in procyclic forms assessed by Western blotting. PUF wt: cells without an inducible transgene (no tetracycline); PUF1+: cells containing the inducible construct grown without tetracycline, already showing some "leakage" from the inducible construct; upward arrow: cells containing the inducible construct grown with tetracycline. Protein loading was equivalent as assessed by staining of the membrane and can also be assessed by the strength of the cross-reacting bands.

possible to obtain better depletion. TbPUF1 protein and transcript down-regulation was most efficient $24 \mathrm{~h}$ after induction (data not shown).

The effect of PUF1 RNAi was also assessed at the protein level, using an affinity-purified anti-peptide antibody. This antibody gives variable cross-reaction with several other proteins, but we could always identify the PUF1 band by routinely includ- ing RNAi or knockout cell extracts in our experiments. TbPUF1 was depleted by RNAi in both forms although residual protein was visible in procyclics (Fig. 2C); accurate measurement of the degree of knockdown was not possible because of the low signals from RNAi cells and the proximity of other cross-reacting proteins on the blots. The RNAi cell lines were grown in the presence and absence of tetracycline for 5 days and growth was monitored every $24 \mathrm{~h}$. None of the cell lines showed any effects of RNAi induction. Either the proteins are not essential, or the protein down-regulation was insufficiently effective to impair growth.

Since PUF1 is most closely related to PUF3 and PUF4, we performed RNAi against pairs of these proteins in order to test functional redundancy. The resulting PUF1/3, PUF1/4 and PUF3/4 double RNAi cell lines showed simultaneous depletion of the two targeted PUF transcripts after tetracycline addition but there was no effect on growth (not shown).

To address the possibility that down-regulation by RNAi was not sufficient and that the residual 20-25\% of TbPUF1 was still able to exert its physiological function, a TbPUF1 knockout was performed in procyclic cells using classical homologous recombination. Contrary to a previous report, we readily obtained cells lacking the TbPUF1 gene, as assessed by Southern, Northern and Western blot analyses (Fig. 2B). These cells grew normally.

We also transfected the knockout constructs into bloodstream forms but were unable to obtain even hemizygous knockouts with a single selectable marker. This failure must be attributed to unknown technical difficulties, such as poor expression of the selectable marker in this locus in bloodstream forms, since down-regulation of PUF1 below the 50\% level had little to no effect in bloodstream forms (this paper and [14]).

\subsection{PUF1 is not associated with polysomes}

To over-express PUF1, we cloned the gene downstream of a tetracycline-inducible RNA polymerase I promoter and generated bloodstream-form and procyclic-form cell lines (Fig. 2D and E). It was previously reported that it was only possible to generate cell lines expressing HA-tagged PUF1 if a portion of the PUF1 mRNA 3 '-untranslated region was included in the constructs [14], but our constructs did not include this region. Addition of tetracycline had no effect on cell growth. To look for binding partners of PUF1, we expressed the protein joined to a C-terminal TAP affinity tag $[31,32]$ in both procyclic and bloodstream forms, and verified expression and cytoplasmic localization by Western blotting and immunofluorescence (not shown). When we purified PUF1-TAP using the tandem affinity procedure no other proteins were found to co-purify in amounts detectable by silver staining, suggesting that any bound partners are either present in low amounts relative to PUF1, or dissociate during purification.

Hoek et al. [14] previously showed that in gel filtration, HAtagged PUF1 eluted between 150 and $500 \mathrm{kDa}$; they also showed that it was mainly cytoplasmic. Since some PUF proteins influence translation, we subjected cell lysates to sedimentation on sucrose gradients. Untagged PUF1 sedimented with the soluble proteins and was clearly not associated with polysomes (Fig. 3) 

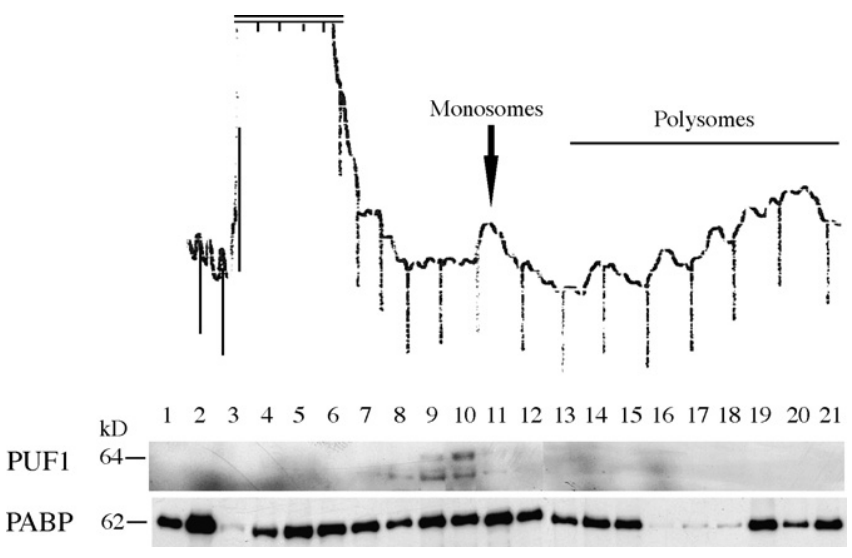

Fig. 3. TbPUF1 migrates approximately with monosomes on sucrose gradients. The upper panel shows the absorption at $260 \mathrm{~nm}$ and the lower panels are Western blots. The upper band on the PUF1 lane is PUF1. As a control the blot was probed with an antibody to poly(A) binding protein [36].

although assembly into smaller complexes and some association with monosomes was possible.

\section{4. $m R N A$ targets of PUF1}

To find out if perturbation of PUF levels in T. brucei influenced steady-state levels of specific mRNAs, we used microarrays to look for mRNAs which were changed at least two-fold after PUF1 RNAi or over-expression [28]. For both procyclic and bloodstream-form RNAi cell lines (the procyclic knockout was obtained later), the down-regulation of PUF1 was readily detected but no other effects on gene expression were found. RNA from over-expressing cells showed, in addition to the expected excess of PUF1 RNA, some increased hybridisation to sequences from ribosomal RNA intergenic regions (e.g. the sequence annotated as Tb927.1.3720). These sequences did not give rise to detectable stable RNAs (not shown). Since the expression vectors integrate into ribosomal RNA spacers, induction of transcription may result in an increase in heterogeneously-sized RNAs originating downstream of the plasmid insertion site.

We also assessed the effects of PUF1 depletion on the proteome. We used the DIGE system (Amersham Biosciences) to compare the global protein levels of T. brucei wild-type cells with procyclic TbPUF1 knockout cells (see Section 2). After RNAi in bloodstream forms, a putative phosphatidyl inositol kinase domain protein (Tb927.3.4020) was up-regulated. The deletion of PUF1 in the procyclic cells resulted in the downregulation of four 2D-gel spots: tryparedoxin peroxidase (Tb09.160.4250) HSP70 (Tb11.01.3110); S-adenosylmethionine synthetase (Tb927.6.4840) and a protein of unknown function (Tb927.5.1710). HSP70, S-adenosylmethionine synthetase and tryparedoxin peroxidase are known to be abundant in trypanosomes and are found in many isoforms on two-dimensional gels [33]; regulation of HSP70 was not confirmed by Western blotting of one-dimensional gels (not shown). Thus, the very minor differences we found are unlikely to be biologically significant.
Table 3

Microarray analyses of RNAs bound to PUF1-TAP in procyclic trypanosomes

\begin{tabular}{ll}
\hline Spot IDs & Sequence \\
\hline 03A12, 14C01, 02D11, 32H10, 44O19, 55D23 & INGI element \\
01K10, 17M19, 26O18 & DIRE repeat \\
47A12, 56D07, 56O4, 46G04 & rRNA \\
28H10 & Tb05.5K5.460 \\
& (VSG pseudogene)
\end{tabular}

PUF1-TAP from trypanosome extracts was bound to IgG sepharose and eluted by TEV protease cleavage. Bound RNA was purified and fluorescent cDNA was synthesised using an oligo d(T) primer. Extracts from cells expressing the TAP tag alone served as controls for cDNA incorporating the alternative fluorescent label. The two labelled preparations were mixed, hybridised to genomic microarrays [28], and spots which hybridised preferentially to the sample from the PUF1-TAP preparations were identified and the inserts sequenced. The table lists the identities of spots which gave $>3$-fold more fluorescence ( $\mathrm{min} / \mathrm{max}$ separation filter 0.1 ) from the PUF1-TAP cDNA than from the TAP-only cDNA in each of two independent purifications. For the first purification, we set a threshold for fitted median intensities of 50,000, and for the second, 25,000.

To look for further evidence of direct regulation of gene expression by PUF1 we purified TAP-tagged PUF1 from procyclic trypanosomes and analysed the bound RNAs using microarrays [34]. The bound RNAs were almost all derived from INGI or DIRE repeat elements (Table 3). None of the detected RNAs corresponded to the proteins which appeared to be regulated in the proteome analysis.

\section{Discussion}

In Drosophila, mammalian cells and yeast, PUF proteins regulate mRNA stability and translation. The aim of this study was to define genuine in vivo targets for regulation by PUF1 in T. brucei. We applied two criteria: first, the target $\mathrm{mRNA}$ is expected to bind to PUF1 in vivo; and second, alterations in PUF1 expression should result in a change in the level of the mRNA or the encoded protein. We used bloodstream forms in which PUF1 expression had been down-regulated by RNAi, procyclic cells with either RNAi or knockout, and over-expressing cells from both lifecycle stages. Gene expression was analysed using microarrays and proteomics and RNAs bound to PUF1 were characterized by affinity purification followed by microarrays. The analyses revealed no targets which satisfied both criteria.

It was previously reported that over-expression of HA-tagged PUF1 resulted in a 1.3-fold increase in the level of ESAG8 mRNA [16]. Small effects on variant surface glycoprotein mRNA half-life were also seen, although steady-state levels were unaffected: there was a slight destabilisation after PUF1 depletion and stabilisation after over-expression. Such small differences would not have been detected in our microarray analysis, which had a cut-off of two-fold. The effects are also the opposite to those expected, since Puf-domain proteins have hitherto universally been described as enhancing mRNA degradation or inhibiting translation [2-4,6].

It was also previously reported that bloodstream trypanosomes over-expressing HA-tagged PUF1 had a growth defect both in culture and in experimental animals [16]. We found, in contrast, that bloodstream and procyclic trypanosomes 
over-expressing wild-type PUF1 or expressing TAP-tagged PUF1 grew normally. Hoek et al. [16] did not measure the extent of PUF1 protein over-expression. There are therefore several possible reasons for the discrepancies between their results and ours. The most likely explanation is that the level of overexpression which we obtained was lower than that achieved by Hoek et al. [16]. Alternatively, it may be that HA-tagged PUF1 is toxic, whereas wild-type PUF1, or PUF1 with a C-terminal TAP tag are not. It may even be that the differences in the mRNA sequences are responsible. Since over-expression of proteins may lead to non-specific effects, it is difficult to interpret the results of such experiments in the absence of an indication of the mechanisms involved.

RNA interference against all nine of the ten TbPUFs individually, and against PUF1/PUF3, PUF1/PUF4 and PUF3/PUF4, had no effect on cell growth. It was previously reported [16] that homozygous deletion of PUF1 was not possible, but we succeeded in procyclic forms and observed no phenotypic effects, Hoek et al. [16] also showed only very transient, minor growth defects when PUF1 was down-regulated to undetectable levels. So far, therefore, there is no convincing evidence that PUF1 is essential for growth of trypanosomes under normal culture conditions. Notably, S. cerevisiae lacking all five PUF proteins are viable [6] although they show changes in the abundance of at least 168 different transcripts (out of 2500 detected) [6]. In contrast, alterations in a single $S$. cerevisiae PUF protein may result in subtle changes which are seen only under particular conditions. Thus, Puf3p binds the COX173'-UTR and promotes rapid deadenylation and decay of the transcript [6], but the effects are only seen under certain nutritional conditions [35]. Similarly, Puf4p appears to destabilise mRNAs only under conditions of transcriptional arrest [35].

TbPUF1 preferentially binds repetitive and transposon-type sequences, but does not have effects on the abundance of equivalent polyadenylated RNAs. We think that the binding is specific since ongoing experiments with other PUF proteins have not shown the same pattern (V.-D. Luu, unpublished results). Results from yeast, however, indicate that simple relationships are not necessarily to be expected. A survey of the binding specificities of all five $S$. cerevisiae Puf proteins revealed that each protein bound to a subset of mRNAs whose products appeared to be functionally linked [34]. Curiously, however, only 12 of the mRNAs that were previously described as being regulated in the PUF1-5 deletion mutant were also found bound to Pufs. Moreover, of 220 putative Puf $3 p$ targets identified by binding studies, only 11 were increased more than two-fold in a $\Delta p u f 3$ mutant [35].

Although we found no defects in PUF-depleted trypanosomes, the proteins are most unlikely to be functionless since the genes are well conserved in different kinetoplastids. Obviously, it is possible that we simply did not deplete the proteins sufficiently for effects to become apparent. Additionally, some $T b$ PUF proteins may be required for differentiation between forms, or for survival as epimastigotes or metacyclic forms. It may also be that PUFs are needed to adapt to stressful conditions which are not encountered during culture. Several of the yeast Puf proteins had overlapping RNA-binding specifici- ties [34]; perhaps in trypanosomes also the various PUFs have overlapping functions. In order to determine the functions of T. brucei PUF proteins it will therefore probably be necessary to determine the binding specificities of all 10 proteins. This information should enable us to design appropriate strategies for further analysis of PUF protein function.

\section{Acknowledgments}

This work was supported by the Deutsche Forschungsgemeinshaft, the German-Israeli foundation (Germany) and the Medical Research Council (UK). We thank George Cross for initially sending DNA clones, and Laurie Read for the anti-PABP antibody. All of the experimental work was done by V.-D. Luu, who also wrote a large proportion of the paper. S. Brems (supervised by J. Hoheisel) made the microarrays and assisted with some of the microarray experiments, D.L. Guilbride supervised the initial phase of the work. The DIGE analysis was done in the laboratory of R. Burchmore, under his direction. C. Clayton supervised overall.

\section{References}

[1] Wickens M, Bernstein DS, Kimble J, Parker R. A PUF family portrait: 3'-UTR regulation as a way of life. Trends Genet 2002;18:150-7.

[2] Murata Y, Wharton RP. Binding of pumilio to maternal hunchback mRNA is required for posterior patterning in Drosophila embryos. Cell 1995;80:747-56.

[3] Wreden C, Verrotti AC, Schisa JA, Lieberfarb ME, Strickland S. Nanos and pumilio establish embryonic polarity in Drosophila by promoting posterior deadenylation of hunchback mRNA. Development 1997;124:3015-23.

[4] Zhang B, Gallegos M, Puoti A, et al. A conserved RNA-binding protein that regulates sexual fates in the $C$. elegans hermaphrodite germ line. Nature 1997;390:477-84.

[5] Souza G, da Silva A, Kuspa A. Starvation promotes Dictyostelium development by relieving PufA inhibition of PKA translation through the YakA kinase pathway. Development 1999;126:3263-74.

[6] Olivas W, Parker R. The puf3 protein is a transcript-specific regulator of mRNA degradation in yeast. EMBO J 2000;19:6602-11.

[7] Tadauchi T, Matsumoto K, Herskowitz I, Irie K. Post-transcriptional regulation through the HO 3'-UTR by Mpt5, a yeast homolog of Pumilio and FBF. EMBO J 2001;20:552-61.

[8] Edwards TA, Pyle SE, Wharton RP, Aggarwal AK. Structure of Pumilio reveals similarity between RNA and peptide binding motifs. Cell 2001;105:281-9.

[9] Wang X, Zamore PD, Hall TM. Crystal structure of a Pumilio homology domain. Mol Cell 2001;7:855-65.

[10] Caro F, Bercovich N, Atorrasagasti C, Levin M, Vazquez M. Trypanosoma cruzi: analysis of the complete PUF RNA-binding protein family. Exp Parasitol 2006;113:112-24.

[11] Zamore PD, Williamson JR, Lehmann R. The Pumilio protein binds RNA through a conserved domain that defines a new class of RNA-binding proteins. RNA 1997;3:1421-33.

[12] Dallagiovanna B, Perez L, Sotelo-Silveira J, Smircich P, Duhagon MA, Garat B. Trypanosoma cruzi: molecular characterization of TcPUF6, a Pumilio protein. Exp Parasitol 2005;109:260-4.

[13] Cui L, Fan Q, Li J. The malaria parasite Plasmodium falciparum encodes members of the Puf RNA-binding protein family with conserved RNA binding activity. Nucleic Acids Res 2002;30:4607-17.

[14] Hoek M, Zanders T, Cross GAM. Trypanosoma brucei expression-siteassociated-gene 8 protein interacts with a Pumilio family protein. $\mathrm{Mol}$ Biochem Parasitol 2002;120:269-84. 
[15] Mea B. The genome of the African trypanosome, Trypanosoma brucei. Science 2005;309:416-22.

[16] Hoek M, Engstler M, Cross GAM. Expression-site-associated gene 8 (ESAG8) of Trypanosoma brucei is apparently essential and accumulates in the nucleolus. J Cell Sci 2000;113:3959-68.

[17] Biebinger S, Wirtz LE, Clayton CE. Vectors for inducible over-expression of potentially toxic gene products in bloodstream and procyclic Trypanosoma brucei. Mol Biochem Parasitol 1997;85:99-112.

[18] Alibu P, Storm L, Haile S, Clayton C, Horn D. A doubly inducible system for RNA interference and rapid RNAi plasmid construction in Trypanosoma brucei. Mol Biochem Parasitol 2004;139:75-82.

[19] van Deursen FJ, Shahi SK, Turner CMR, Hartmann C, Guerra-Giraldez C, Matthews KR. Characterisation of the growth and differentiation in vivo and in vitro of bloodstream-form Trypanosoma brucei strain TREU 927. Mol Biochem Parasitol 2001;112:163-72.

[20] Clayton CE, Estévez AM, Hartmann C, Alibu VP, Field M, Horn D. In: Carmichael G, editor. Down-regulating gene expression by RNA interference in Trypanosoma brucei in RNA interference. Humana Press; 2005.

[21] Redmond S, Vadivelu J, Field MC. RNAit: an automated web-based tool for the selection of RNAi targets in Trypanosoma brucei. Mol Biochem Parasitol 2003;128:115-8.

[22] Maier A, Lorenz P, Voncken F, Clayton CE. A essential dimeric membrane protein of trypanosome glycosomes. Mol Microbiol 2001;39:1443-51.

[23] Estévez A, Kempf T, Clayton CE. The exosome of Trypanosoma brucei. EMBO J 2001;20:3831-9.

[24] Guerra-Giraldez C, Quijada L, Clayton CE. Compartmentation of enzymes in a microbody, the glycosome, is essential in Trypanosoma brucei. J Cell Sci 2002;115:2651.

[25] Clayton CE. Import of fructose bisphosphate aldolase into the glycosomes of Trypanosoma brucei. J Cell Biol 1987;105:2649-53.

[26] Djikeng A, Shi H, Tschudi C, Shen S, Ullu E. An siRNA ribonucleoprotein is found associated with polyribosomes in Trypanosoma brucei. RNA 2003;9:802-8
[27] Diehl S, Diehl F, El-Sayed NM, Clayton CE, Hoheisel JD. Analysis of stage-specific gene expression in the bloodstream and the procyclic form of Trypanosoma brucei using a genomic DNA microarray. Mol Biochem Parasitol 2002;123:115-23.

[28] Brems S, Guilbride DL, Gundlesdodjir-Planck D, et al. The transcriptomes of Trypanosoma brucei Lister 427 and TREU927 bloodstream and procyclic trypomastigotes. Mol Biochem Parasitol 2005;139:16372.

[29] Fellenberg K, Hauser NC, Brors B, Neutzner A, Hoheisel JD, Vingron M. Correspondence analysis applied to microarray data. Proc Natl Acad Sci USA 2001;98:10781-6.

[30] Fellenberg K, Hauser NC, Brors B, Hoheisel JD, Vingron M. Microarray data warehouse allowing for the statistical analysis of experiment annotations. Bioinformatics 2002;18:423-33.

[31] Puig O, Caspary F, Rigaut G, et al. The tandem affinity purification (TAP) method: a general procedure of protein complex purification. Methods 2001;24:218-29.

[32] Rigaut G, Shevchenko A, Rutz B, Wilm M, Mann M, Seraphin B. A generic protein purification method for protein complex characterization and proteome exploration. Nat Biotechnol 1999;17:1030-2.

[33] Jones A, Faldas A, Foucher A, et al. Visualisation and analysis of proteomic data from the procyclic form of Trypanosoma brucei. Proteomics 2006;6:259-67.

[34] Gerber A, Herschlag D, Brown P. Extensive association of functionally and cytotopically related mRNAs with Puf family RNA-binding proteins in yeast. PLoS Biol 2004;2:e79.

[35] Foat B, Houshmandi S, Olivas W, Bussemaker H. Profiling conditionspecific, genome-wide regulation of mRNA stability in yeast. Proc Natl Acad Sci U S A 2005; 102:17675-80.

[36] Hotchkiss TL, Nerantzakis GE, Dills SC, Shang L, Read LK. Trypanosoma brucei poly(A) binding protein I cDNA cloning, expression, and binding to $5^{\prime}$-untranslated region sequence elements. Mol Biochem Parasitol 1999;98:117-29. 